\author{
DETERMINATION OF PARAMETERS AFFECTING THE USE OF COMPLEMENTARY AND \\ ALTERNATIVE MEDICINE IN CANCER PATIENTS AND DETECTION OF PREVALENCE OF \\ USE
}

\author{
${ }^{1}$ Alpaslan Mayadagli, ${ }^{1}$ Atinc Aksu, ${ }^{2}$ Fatih Goksel, ${ }^{3}$ Erkan Gocen, ${ }^{4}$ Eray Karahacioglu, ${ }^{1}$ Mahmut \\ Gumus and ${ }^{4}$ Yücel Pak,
}

${ }^{1}$ Kartal Education Hospital, Istanbul, Turkey, ${ }^{2}$ Erzurum State Hospital, Erzurum, Turkey, ${ }^{3}$ Kayseri State Hospital, Kayseri, Turkey, ${ }^{4}$ Gazi Medical School, Ankara, Turkey

E-mail: mgumus@superonline.com

\begin{abstract}
This study was conducted to find out the frequency of complementary and alternative medicine (CAM) use that could lead to troubles in patient health and in applied standard therapy protocols when used improperly, which method is used, the reasons for use and from which resources the information about this topic were obtained. A questionnaire consisting of 28 questions was applied to 195 patients with cancer diagnosis by a face-to-face interview. The obtained data were assessed with SPSS 11.5 program. Out of 195 cancer patients, 100 (51.3\%) were using CAM and 48.7\% (n=95) were not. The most commonly used agent was nettle (72\%). This was followed by herbal teas (21\%), grape molasses (20\%) and black seed (20\%). The frequency of CAM use was found higher in those under age 50, in literate people, in those working during the diagnosis stage and having disease at the later stage. While CAM was commonly recommended by friends and relatives of the patients (73\%), this ratio was only $5 \%$ for health professionals. While $51.3 \%$ of all patients were gathering information about CAM, $75 \%$ of those actually using CAM gathered information about it. Whilst information was gathered mostly from the relatives of patients and tamperers (47\%), it can be gathered from physicians only with a ratio of $10 \%$. Cancer patients use CAM and they gather information mainly from unreliable sources rather than physicians. Although the primary information source should be physicians, the ratio for this was very low (10\%). We suggest that physicians should spend more time in gathering correct information and sharing them with their patients for a better guidance.
\end{abstract}

Keywords: Complementary medicine, alternative medicine, complementary therapies, cancer.

\title{
Introduction
}

Even though rapid developments occur in cancer therapy, because the therapy continues for a long time, the success rates are still low with uncertainty and desperation, cancer patients can tend to choose methods other than medical care. Complementary and alternative medicine (CAM) is used very commonly among the cancer patients. In recent studies, it was shown that one third of these patients have been using CAM (Ernst and Cassileth, 1998). The reasons for using CAM are to provide a support to the applied therapy, prevent the recurrence of the disease, increase the quality of life, support the immune system and increase survival (Henderson and Donatelle. 2004, Richardson et al. 2000, Shen et al. 2002). The frequency of CAM use demonstrates difference in terms of the primary disease and the country. In a study performed in patients with breast cancer, CAM use was 20\% in Canada (Gray et al. 2003), 22.4\% in England ( Rees et al. 2000), and more than 60\% in the United States (Ashikaga et al. 2002, VandeCreek et al. 1998). On the other hand, CAM use in patients with breast cancer was $44.7 \%$ and it was 32\% in patients with colorectal cancer (Molassiotis et al. 2006, Molassiotis et al. 2005). This study was conducted to describe CAM use in Turkey because of the differences in CAM use between countries in the literature. Furthermore, studies about CAM use are not sufficient in order to reinforce the results of the data obtained from the previous studies and to reveal how often the patients use CAM and their reasons for use.

\section{Materıal and Methods}

A questionnaire consisting of 28 questions was applied to 195 patients with cancer diagnosis in the Department of Radiation Oncology, Dr. Lütfi Kırdar Kartal Training and Research Hospital and in the Department of Radiation Oncology, Gazi 
University Faculty of Medicine. A questionnaire prepared by our institute review committee was applied. The questionnaire was applied by a physician in a face-to face interview. The questions were mainly directed to reveal socio-demographic characteristics of the patients (Table 1), reasons for use of CAM and the information source. The obtained data were assessed in SPSS 11.5 program.

\section{Results}

Hundred and seven (54.9\%) patients were males and 88 (45.1\%) were females. The median age was 56 years (range 1596). In terms of pathological diagnosis, the largest group consisted of patients with pulmonary cancer ( $n=49,25.1 \%$ ), followed by those with gastrointestinal system cancer $(n=33,16.9 \%)$ and breast cancer $(n=33,16.9 \%)$ (Table 2). Fifty-one point three percent of the patients ( $n=100)$ were using CAM, whereas $48.7 \%(n=95)$ of them were not. Nettle was used most commonly $(72 \%)$. This was followed by herbal teas (21\%), grape molasses (20\%) and black seed (20\%) (Table 3).

The use of CAM was found similar in both males and females. CAM use was detected more in the younger ages. While CAM use is $62.4 \%$ for patients younger than 50 years old, it was $46.5 \%$ in those above 50 years $(p=0.02)$. The educational level was decisive in the use of CAM. While the use of CAM was $33.35 \%$ in illiterate people, it was $53.4 \%$ in literate ones ( $\mathrm{P}=0.06)$. The use of CAM was found higher in patients actively working during disease period compared to those who did not work $(64.9 \%$ vs $48.1 \%$, $\mathrm{p}=0.04)$. CAM use was found higher in those with advanced disease compared to those with early disease. But, this did not translate into a statistical significance $(\mathrm{p}=0.07)$. The frequency for CAM use in terms of socio-demographic characteristics of the patients is given in table 4 .

CAM was recommended to $38 \%$ of the patients by friends, $35 \%$ of them by the relatives and $1 \%$ by the auxiliary health professionals (Figure 1). Eleven percent of patients using CAM did not want to use it but forced by their families whereas $5 \%$ of these patients wanted to use it but rejected by their families. While $69 \%$ of the patients using CAM have thought that it is beneficial, $49 \%$ of them stated that they had benefits from CAM. Fifteen percent of patients using CAM were worried that the substance they used would disrupt their health and undesirable side effects were seen in $8 \%$ of the patients. While $5 \%$ of the patients used CAM because they did not benefit from the medical therapies, $95 \%$ of them used CAM as supplement to medical therapies.

While $51.3 \%$ of all patients ( $n=195)$ were attempted to gather information about CAM, $75 \%$ of the patients using CAM $(\mathrm{n}=100)$ endeavored for it. Information about CAM was obtained from relatives (27\%), tamperers (20\%), television $(11 \%)$, internet (11\%), physicians (10\%) and books (5\%) (Figure 2).

\section{Discussion}

In this study, $51.3 \%$ of 195 patients ( $\mathrm{n}=100)$ were found to use CAM. Although this number was found similar in several studies (Molassiotis et al. 2006, Paltiel et al. 2001), there are other studies showing lower CAM use (Wyatt et al. 1999, Pud et al. 2005, Molassiotis et al. 2006b). Socio-cultural characteristics and life-style of people are seen as primary factors responsible for these variations in the results of these studies (Pud et al. 2005). In the multinational study conducted by Molassiotis involving patients with breast cancer, it was seen that the use of CAM showed significant differences among different countries. The use of CAM was most common in Italy (73.3\%) and least common in Greece (15.8\%). CAM use was 58.3\% in Turkey (Molassiotis et al. 2005). The mean incidence of CAM use was found as $31.4 \%$ in a review of previous international studies done in 13 countries (Ernst and Cassileth, 1998). Beside the cultural differences, the primary region where the disease has begun was one of the factors affecting the use of CAM. The frequencies of CAM use for lung disease, for colorectal disease (Molassiotis et al. 2005) and for patients with breast cancer (Molassiotis et al. 2006b) were reported as 23.6\%, 32\% and 44.7\%, respectively.

In the studies conducted until now, herbal therapies have been the most commonly applied CAM method Molassiotis et al. 2006, Molassiotis et al. 2005, Pud et al. 2005). The type of the disease, the stage of the disease and the presence of the symptoms were determinant in CAM use. While the patients in advanced stage use religious and relaxing therapies, the patients in earlier stage use homeopathy and acupuncture. Furthermore, cultural state, environment, customs and the religious beliefs were also determinant factors in CAM use (Pud et al. 2005). In an Israeli study, religious, herbal and relaxation therapies were more common (Pud et al. 2005) whereas in other studies, homeopathy (Bernstein et al. 1996, Kitai et al. 1998) or acupuncture and shiatsu were used more commonly (Soffer et al. 2001). 
Table 1: Socio-demographical characteristics of the patients

\begin{tabular}{|c|c|}
\hline & Number of patients [N (\%)] \\
\hline \multicolumn{2}{|l|}{ Age } \\
\hline$<50$ years old & $53(27.2 \%)$ \\
\hline$>50$ years old & $142(72.8 \%)$ \\
\hline \multicolumn{2}{|l|}{ Gender } \\
\hline Male & 107 (54.9\%) \\
\hline Female & 88 (45.1\%) \\
\hline \multicolumn{2}{|l|}{ Education } \\
\hline Illiterate & $21(10.8 \%)$ \\
\hline Primary School & $49(76.4 \%)$ \\
\hline Higher Education & $25(12.8 \%)$ \\
\hline \multicolumn{2}{|l|}{ Profession } \\
\hline Retired & 22 (11.3\%) \\
\hline House wife & 76 (39\%) \\
\hline Employee & $28(14.4 \%)$ \\
\hline $\begin{array}{l}\text { Worker- self } \\
\text { employment }\end{array}$ & $69(35.4 \%)$ \\
\hline \multicolumn{2}{|l|}{$\begin{array}{l}\text { Job Condition during } \\
\text { the disease period }\end{array}$} \\
\hline Working & 37 (19\%) \\
\hline No job & $158(81 \%)$ \\
\hline \multicolumn{2}{|l|}{ Habitation } \\
\hline City & 150 (76.9\%) \\
\hline County-town-village & 45 (23.1\%) \\
\hline \multicolumn{2}{|l|}{ Diagnosis Time } \\
\hline$<6$ months & $122(62.6 \%)$ \\
\hline$>6$ months & 73 (37.4\%) \\
\hline \multicolumn{2}{|l|}{ Disease Stage } \\
\hline Local stage & 157 (80.5\%) \\
\hline Distant metastasis & 38 (\%19.5) \\
\hline
\end{tabular}

Table 2: Distribution of Patients according to type of cancer

\begin{tabular}{ll}
\hline Type of cancer & Number of Patients [N (\%)] \\
\hline Lung & $49(25.1 \%)$ \\
Gastrointestinal system & $33(16.9 \%)$ \\
Breast & $33(16.9 \%)$ \\
Head and Neck & $16(8.2 \%)$ \\
Prostate & $(6.2 \%)$ \\
Gynecology & $12(6.2 \%)$ \\
Soft tissue & $11(5.6 \%)$ \\
Lymphoma & $9(4.6 \%)$ \\
Central Nerve System & $6(3.1 \%)$ \\
Other & $14(7.2 \%)$ \\
\hline
\end{tabular}


Table 3: Preferences of patients in use of CAM

\begin{tabular}{ll}
\hline & Number of Patients \\
& {$[\mathbf{N}(\%)]$} \\
\hline Nettle & $72(72 \%)$ \\
Herbal Teas (cherry stalk, wine leaf, daisy tea,sage, thyme juice...) & $21(21 \%)$ \\
Molasses (pomegranade molasses, grape molasses, mulberry molasses, chestnut honey, & \\
honey...) & $20(20 \%)$ \\
Black Seed & \\
Vegetables (broccoli, artichoke, chilly pepper, parsley, garlic and lemon, tomatoes & $20(20 \%)$ \\
juices...) & $19(19 \%)$ \\
Wasp pollen & $14(14 \%)$ \\
Carob & $10(10 \%)$ \\
Linen seed & $8(8 \%)$ \\
Frark cartilage & $7(7 \%)$ \\
Belief therapy (amulet, reiki...) & $7(7 \%)$ \\
Donkey milk & $4(4 \%)$ \\
& $1(1 \%)$ \\
\hline
\end{tabular}

CAM: Complementary and alternative medicine

Table 4: Use of CAM in terms of socio-demographic characteristics

\begin{tabular}{|c|c|c|}
\hline & Use of CAM [N (\%)] & P value \\
\hline Age & & 0.020 \\
\hline$<50$ years old & $36(64.2 \%)$ & \\
\hline$>50$ years old & $66(46.5 \%)$ & \\
\hline Gender & & $>0.05$ \\
\hline Male & 55 (1.4\%) & \\
\hline Female & $45(51.1 \%)$ & \\
\hline Education & & 0.060 \\
\hline Illiterate & $7(33.3 \%)$ & \\
\hline Literate & $93(53.4 \%)$ & \\
\hline Profession & & $>0.05$ \\
\hline Retired & 10 (45.5\%) & \\
\hline House wife & $38(50 \%)$ & \\
\hline Employee & 19 (67.9\%) & \\
\hline $\begin{array}{l}\text { Worker- self } \\
\text { employment }\end{array}$ & $33(47.8 \%)$ & \\
\hline $\begin{array}{l}\text { Job Condition during } \\
\text { the disease period }\end{array}$ & & 0.040 \\
\hline Working & $24(64.9 \%)$ & \\
\hline No job & $76(48.1 \%)$ & \\
\hline Habitation & & $>0.05$ \\
\hline City & $80(53.3 \%)$ & \\
\hline County-town-village Diagnosis Time & $20(44.4 \%)$ & \\
\hline$<6$ months & & $>0.05$ \\
\hline$>6$ months & $59(48.4 \%)$ & \\
\hline Disease Stage & $41(56.2 \%)$ & \\
\hline Local stage & & 0.070 \\
\hline Advanced stage & $\begin{array}{l}7(48.4 \%) \\
24(63.2 \%)\end{array}$ & \\
\hline
\end{tabular}

CAM: Complementary and alternative medicine 


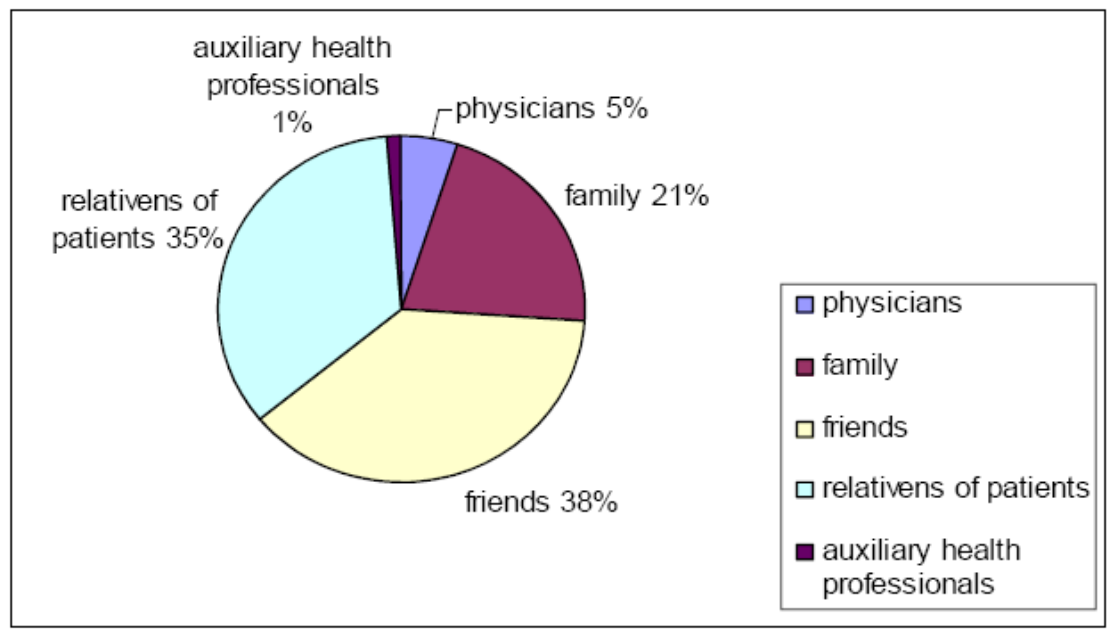

Figure 1: The source of recommendation for CAM use

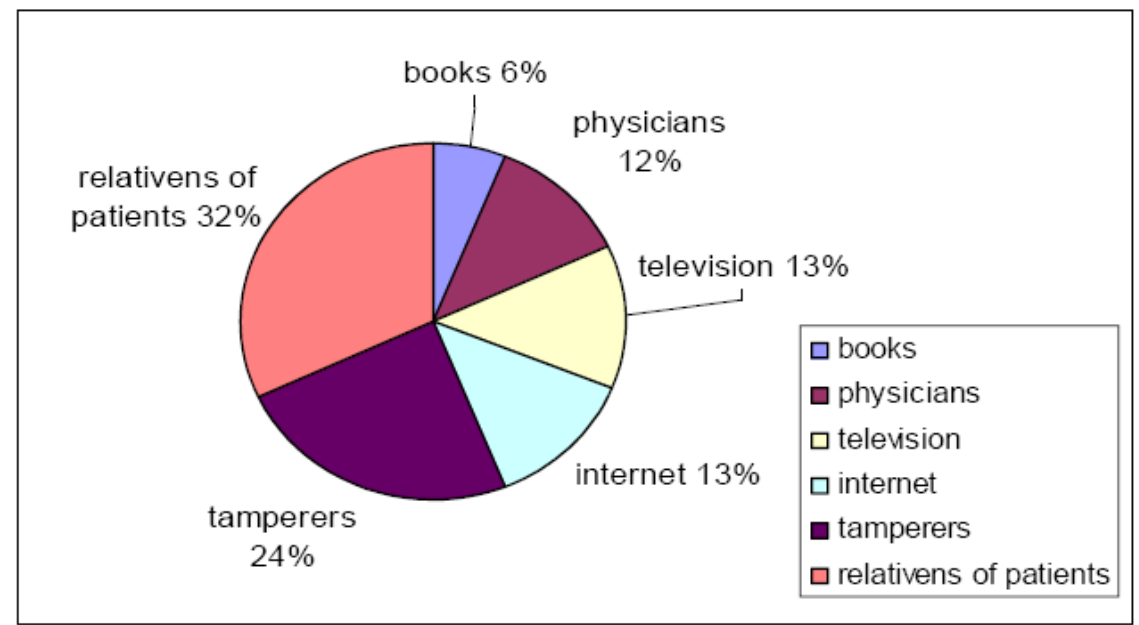

Figure 2: The resources used by the CAM using patients to gather information

In our study, herbal therapies were most commonly used. Among the herbal therapies, nettle was (72\%) in the first rank. However, although it was less often, carob $(11 \%)$ or donkey milk was noticeable. Physicians must spend more time with their patients to prevent them desperately choose unacceptable CAM methods. The use of CAM was found higher in young patients and in those with higher educational level (Bernstein et al. 1996, Soffer et al. 2001, Azaz-Livshits T et al. 2002). Considering more active life style of young patients with higher education and their ability to reach information easily, higher frequency of CAM use can be explained. In our study, we also found higher CAM use in young patients with higher education when compared to illiterate patients, working patients and patients with later-stage disease. There are physical and social factors that lead the cancer patients to use CAM. These causative factors are to support the body in fighting with cancer (Molassiotis et al. 2006, Molassiotis et al. 2005), to increase the expectation of the patient (Richardson et al. 2000), the fact that the applied medical therapy does not meet the expectations, the feeling of desperation and the fact that the patient does not trust to his or her physician completely (Paltiel et al. 2001).

Reports indicating that therapies with herbal and animal origin negatively affect the activity of the medical therapy have been presented. Furthermore, toxicities of herbal therapies have been reported (Ernst, 2000). The side effects were reported as 2.1\% (Molassiotis et al. 2005, Molassiotis et al. 2006b) or 25\% in a different study (Pud et al. 2005). In two studies by Molassiotis (Molassiotis et al. 2005, Molassiotis et al. 2006b) 4.3\% and 6.5\% of the patients reported that they had no benefits from CAM. On the other hand, while $40 \%$ of the patients using CAM were thinking that they had improvement in their health, $34.3 \%$ of them thought that they had improvement in their physical health (Pud et al. 2005). It was noticed that patients using 
CAM were more optimistic than those that do not use CAM (Wyatt et al. 1999). In our study, while 69\% of the patients using CAM thought that it is beneficial, $49 \%$ of them stated that they received benefits. While $15 \%$ of the patients using CAM were worrying that the used substance will disrupt their health, side effects developed in $8 \%$ of them. In the majority of the studies done, the information is received most commonly from friends, from media and from family. The role of the physicians is quite low in this sense $(17.9 \%, 12.5 \%)$ (Molassiotis et al. 2005, Molassiotis et al. 2006b). In our study, only 10\% of the patients got information from their physicians, 5\% of them used CAM with the advice of physicians. Nevertheless, because most of the information were received from the friends and the relatives. It was evident that that the information about this topic is not sufficient.

In conclusion, we found that more than a half of the patients use CAM and only $10 \%$ of them get information from physicians. Because the CAM method used by the patients negatively affect medical therapy, it is very important to manage these patients correctly. Physicians must give appropriate explanations that will meet the needs of the patients.

\section{References}

1. Ashikaga T, Bosompra K, O’Brien P, Nelson L (2002). Use of complimentary and alternative medicine in breast cancer patients: prevalence, patterns and communication with physicians. Support Care Cancer; 10: 542-548.

2. Azaz-Livshits T, Muszkat M, Levy M (2002). Use of complementary alternative medicine in patients admitted to internal medicine wards. International Journal of Clinical Pharmacology \& Therapeutics;40(12): 539-547.

3. Bernstein JH, Shmueli A, Shuval JT (1996). Consultations with practitioners of alternative medicine. Harefuah;130(2): 83-85.

4. Ernst E (2000). Possible interactions between synthetic and herbal medicinal products. Part I: a systematic review of the indirect evidence. Perfusion;13: 4-6.

5. Ernst E, Cassileth BR (1998). The prevalence of complementary/alternative medicine in cancer: a systematic review. Cancer;83: 777-82.

6. Gray RE, Fitch M, Goel V, Franssen E, Labrecque M (2003). Utilization of complementary/alternative services by women with breast cancer. J Health Soc Policy;16: 75-84.

7. Henderson JW, Donatelle RJ (2004). Complementary and alternative medicine use by women after completion of allopathic treatment for breast cancer. Altern Ther Health Med;10: 52-57.

8. Kitai E, Vinker S, Sandiuk A, Hornik O, Zeltcer C, Gaver A (1998). Use of complementary medicine among primary care patients. Family Practice ;15: 411-414.

9. Molassiotis A, Panteli V, Patiraki E, Ozden G, Platin N, Madsen E, Browall M, Fernandez-Ortega P, Pud D, Margulies A (2006). Complementary and alternative medicine use in lung cancer patients in eight European countries. Complementary Therapies in Clinical Practice;12: 34-39.

10. Molassiotis A, Fernandez-Ortega P, Pud D, Ozden G, Platin N, Hummerston S, Scott JA, Panteli V, Gudmundsdottir G, Selvekerova S, Patiraki E, Kearney N (2005). Complementary and alternative medicine use in colorectal cancer patients in seven European countries. Complementary Therapies in Medicine;13: 251-57.

11. Molassiotis A, Scott JA, Kearney N, Pud D, Magri M, Selvekerova S, Bruyns I, Fernadez-Ortega P, Panteli V, Margulies A, Gudmundsdottir G, Milovics L, Ozden G, Platin N, Patiraki E (2006b). Complementary and alternative medicine use in breast cancer patienta in Europe. Support Care Cancer;14: 260-267.

12. Paltiel O, Avitzour M, Peretz T, Cherny N, Kaduri L, Pfeffer RM, Wagner N, Soskolne V (2001). Determinants of the use of complementary therapies by patients with cancer. J Clin Oncol:19; 2439-48.

13. Pud D, Kaner E, Morag A, Ben-Ami S, Yaffe A (2005). Use of complementary and alternative medicine among cancer patients in Israel. European Journal of Oncology Nursing; 9: 124-130.

14. Rees RW, Feigel I, Vickers A, Zollman C, McGurk R, Smith C (2000). Prevalence of complementary therapy use by women with breast cancer: a population based survey. Eur J Cancer; 36: 1359-64.

15. Richardson MA, Sanders T, Palmer JL, Greisinger A, Singletary SE (2000). Complementary/alternative medicine use in a comprehensive cancer center and the implications for oncology. J Clin Oncol;18: 2505-14.

16. Shen J, Andersen R, Albert PS, Wenger N, Glaspy J, Cole M, Shekelle P (2002). Use of complementary/alternative therapies by women with advanced-stage breast cancer. BMC Complement Altern Med ;13:2, 8.

17. Soffer T, Press Y, Peleg A, Friger M, Ganel U, Peleg R (2001). Characteristics of patients at a complementary medicine clinic in Beer Sheva: summary of the first two years of operation. Israel Medical Association Journal;3(8): 584-588.

18. Wyatt GK, Friendman LL, Given BA, Beckrow KC (1999). Complementary therapy use among older cancer patients. Cancer Pract; 7: 136-44.

19. VandeCreek L, Rogers E, Lester J (1998). Use of alternative therapies among breast cancer outpatients compared with the general population. Altern Ther Health Med;5: 71-76 